\title{
ANALYSIS OF HOT DEFORMATION BEHAVIOR AND FORECASTING DAMAGE IN THE FORGING PROCESS OF WASPALOY ALLOY
}

\author{
M. Kukuryk*, J. Winczek ${ }^{* * *}$, M. Gucwa***
}

\begin{abstract}
In this paper, the analysis of the three-dimensional strain state for the cogging process of forgings made of the Waspaloy alloy with the application of the finite element method was presented. For the numerical simulations, a commercial and professional plastic forming software DEFORM 3D (2018) was applied. The results of work connected with the simulation of the diagram of metal flow and thermal phenomena in the hot forging process in $V$-shaped anvils, which were complemented by means of the addition of forecasting the damage in the course of forging, were presented. The assessment of the distribution of the effective stress, the mean stress, temperature, and also the damage factor in the volume of the billet being strained was performed. Good agreement between theoretical and experimental results was observed.
\end{abstract}

Keywords: cogging, Waspaloy alloy, FEM, damage

\section{Introduction}

A Waspaloy alloy, having a nickel matrix, is an instance of a billet fulfilling the requirements relevant to an advantageous combination of creep resistance and thermal resistance with thermal fatigue resistance and corrosion resistance. The major features of this alloy include a good combination of creep strength, thermal stability and weldability, which was confirmed in the work (Lin, Wen et al., 2014). A significant part of high-strength construction elements of this alloy is subjected to cogging process or die forging. For that very reason, research encompassed within the scope of designing these responsible construction elements functioning at elevated temperatures and transferring rapidly-changing cycles of mechanical loads ought to provide a comprehensive selection of the appropriate thermal-mechanical conditions of the process of the plastic strain of the Waspaloy alloy to fulfill the objective of obtaining high and stable functional properties of the final products (Lin, Chen et al., 2014). Because of the high contents of nickel and chromium in the alloy being analysed, major features of it include the low level of plastic properties and a comparatively narrow scope of the temperatures of forging. For that very reason, it is required that the determined technological conditions are rigorously followed in the process of initial processing of an initial structure of an ingot (Wang et al., 2013). In addition to that, the natural heterogeneousness of the structure and defects of the initial billet, and also the heterogeneousness of strains, resulting from the process of technological forging, bring about a number of serious technological problems in the course of forging the Waspaloy alloy in industrial conditions (Swiątoniowski et al., 2012). The possibility of forecasting the place and the phase of strain, in which the loss of the cohesiveness of a plasticallydeformed billet, eliminating the existing discontinuities, and also preventing the formation of the new ones, brings about a large number of problems, and is an indispensable element of the correct design of the process of the technological forging of the Waspaloy alloy (Lin, Deng et al., 2014). In this paper, the

\footnotetext{
PhD. Marcin Kukuryk: Technical University of Czestochowa, Faculty of Mechanical Engineering and Computer Science, Street Dabrowskiego 69, 42-200, Czestochowa, PL, kukurykm@itm.pcz.pl

** Prof. Jerzy Winczek, PhD. : Technical University of Czestochowa, Faculty of Mechanical Engineering and Computer Science, Street Dabrowskiego 69, 42-200, Czestochowa, PL,winczek@imipkm.pcz.czest.pl

*** PhD. Marek Gucwa: Technical University of Czestochowa, Faculty of Mechanical Engineering and Computer Science, Street Dabrowskiego 69, 42-200, Czestochowa, PL, mgucwa@spaw.pcz.pl
} 
model was developed upon the basis of the finite element method, making it possible to simulate the diagram of metal flow, thermal phenomena and a phenomenological model of damage in the course of forging the Waspaloy alloy in selected V-shaped anvils.

\section{Methods}

For a three-dimensional modelling of plastic metal flow in the course of cogging process of the Waspaloy alloy, using the commercial software DEFORM-3D, composed of mechanical and thermal part, and forecasting damage, was taken advantage of. In order to find the solution, the finite element method, combined with finding the solution to the Fourier equation for non-stationary heat flow, was applied. A precise description of the developed thermal-mechanical model of the forging process was provided in the work of Kukuryk (2015). As a result of the initial verification of various criteria of damage for forecasting the loss of cohesiveness in the process of cogging process, the Normalized criterion of D.J. Latham and M.G. Cockcroft, which is expressed as follows:

$$
\int_{0}^{\bar{\varepsilon}_{f}} \frac{\sigma^{*}}{\bar{\sigma}} d \bar{\varepsilon}(t) \geq C
$$

where $\bar{\sigma}$ is the true effective stress, $\bar{\varepsilon}$ is the true effective strain, $\bar{\varepsilon}_{f}$ is the effective strain when fracture occurs, $\sigma^{*}$ is the maximum principle stress, $C$ is the critical value of ductile fracture.

In numerical calculations, and also in experimental research, the dimension of the billet is $\varnothing 80 \mathrm{~mm} \times 200$ $\mathrm{mm}$, made of the Waspaloy alloy having the following chemical composition: Ni-58\%, Cr-19\%, Co13.6\%, Mo-4.4\%, Ti-3.1\%, Al-1.5\%, Fe-2.0\%, Mn-0.1\%, Si-0.15\%, C-0.09\% and, B- $0.006 \%$. An initial temperature of the billet was assumed to be $1050{ }^{\circ} \mathrm{C}$, whereas the initial temperature for anvils was determined as amounting to $350{ }^{\circ} \mathrm{C}$. Forging was conducted in two consecutive passes following $90^{\circ}$ rotating of the billet, with simultaneous maintaining (in every pass) the constant value of the height reduction $\varepsilon_{h}=0.35$ and constant relative feed amounting to $l_{w}=0.75$. Forging was conducted on a hydraulic press having the pressure of $2.5 \mathrm{MN}$. The top and bottom anvils are all V-shape with $200 \mathrm{~mm}$ width and $105^{\circ} \times 135^{\circ}$ angle, was presented in Figure 1a. The verification of the developed model for the alloy being analysed was conducted by means of comparing obtained results of calculations with experimental data.

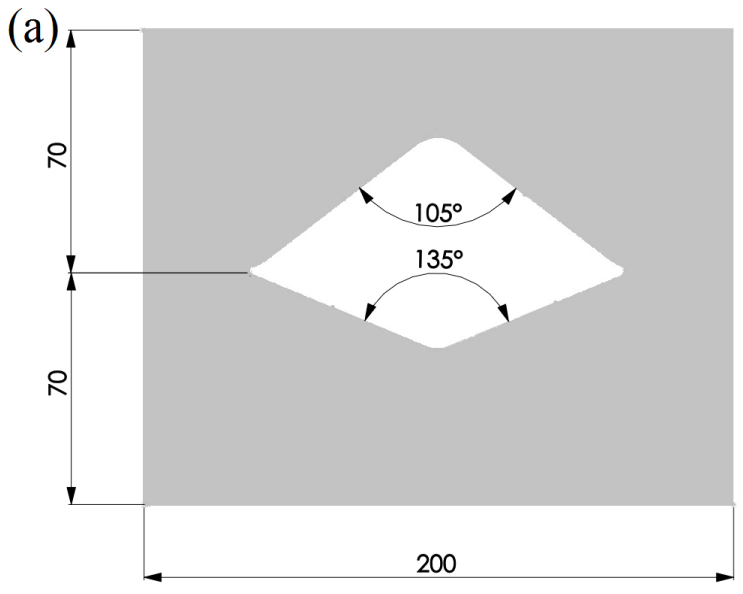

(b)

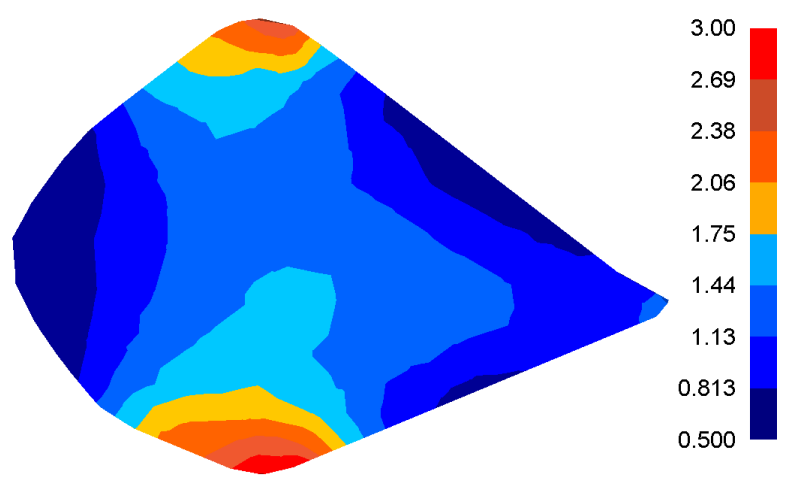

Fig. 1: (a) Shape of the asymmetrical V-shape anvils, (b) distribution of effective strain after the cogging process (after the second pass, $\varepsilon_{h}=0.70$ ).

\section{Results and analyses}

The values of the flow stress for the Waspaloy alloy, indispensable for numerical calculations, was assumed upon the basis of conducted experimental plastometric research for various values of strain, the strain rate, and for the determined scope of the temperature of hot plastic deformation $\left(\sigma_{p}=f\left(\varepsilon_{h}, \dot{\varepsilon}, T\right)\right)$, in accordance with the methodology of research presented in a article (Kukuryk, 2015). The conducted computer simulations made it possible to determine the local values being major 
features of the strain state, the stress state, distribution of temperature, and also the distributions of the damage factor in the course of cogging process the alloy being researched. The distribution of the effective strain following the second pass $\left(\varepsilon_{h}=0.70\right)$ in asymmetrical $\mathrm{V}$-shape anvils was presented in Figure $1 \mathrm{~b}$. The greatest values of the effective strain were found in a large area of the central part of the deformation valley, and exceeded the value of a set strain $\left(\varepsilon_{i}=1.44-1.75\right)$, which was exerting an advantageous influence upon its good plastic deformation. The area adjacent to the surface of anvils, and also the side zones of the forging, were the areas of a significantly smaller effective strain $\left(\varepsilon_{i}=0.81-1.13\right)$. A comparatively large contact surface of the strained billet with a tool was the reason for the advantageous stress state in the central part of the forging (Figure 2a).
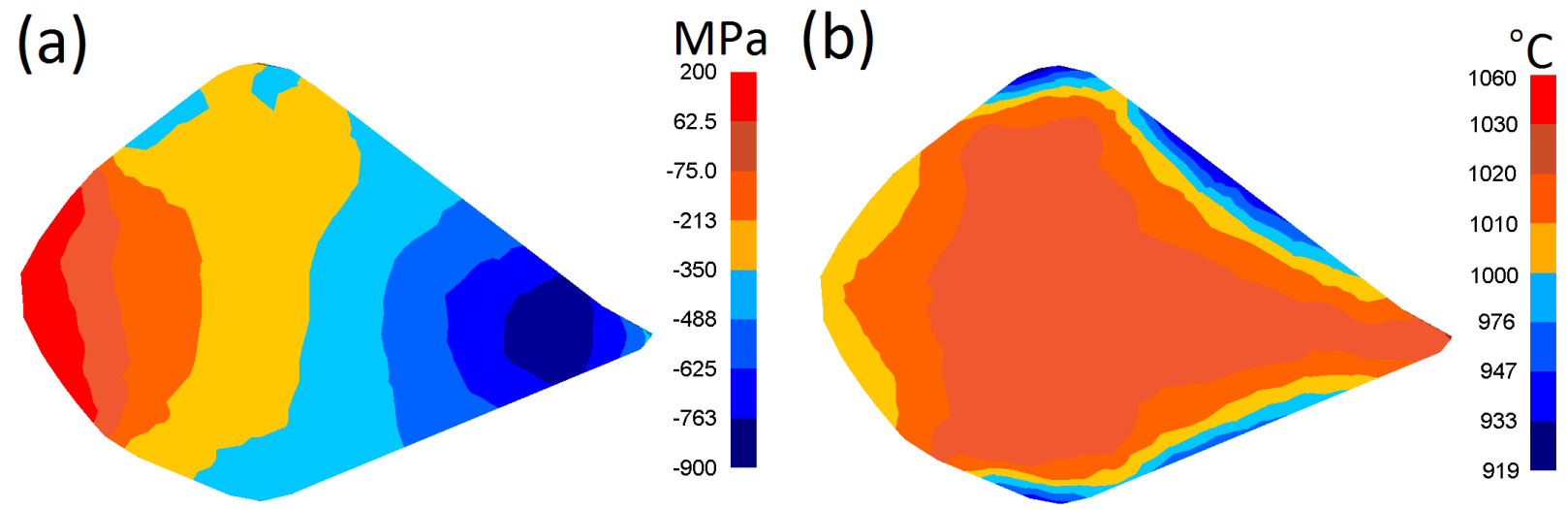

Fig. 2: Distribution of mean stress (a) and temperature (b) after the cogging process $\left(\varepsilon_{h}=0.70\right)$.

The presented distribution of mean stresses indicates the possibility of the occurrence of tensile stresses exclusively on very small areas, situated in the side zones of a forging. The forging process was accompanied by a stable temperature on a large area of the central zone of a forging, brought about by the emission of plastic strain heat, and a low thermal conductivity of the strained alloy. The contact of a hot metal with cooler tools brought about decrease in a temperature in the vicinity of contact surfaces by $\Delta T=130{ }^{\circ} \mathrm{C}$ (Figure 2b). In the course of forging in asymmetrical $\mathrm{V}$-shape anvils, a high uniformity of the distribution of the damage factor $\psi_{C L}$ was observed. In the large axial zone of a forging, the lowest values of factor $\psi_{C L}=0.03$ were obtained ; exclusively in a small part of the size zones of a forging, and also under edge radii of the tops of anvils, the higher values of this factor were obtained (Figure 3a).

(a)

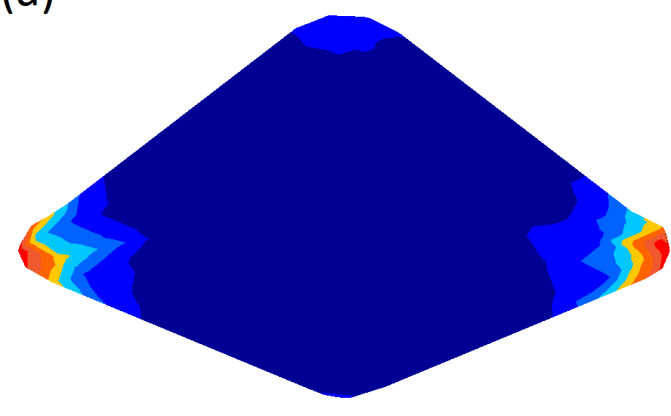

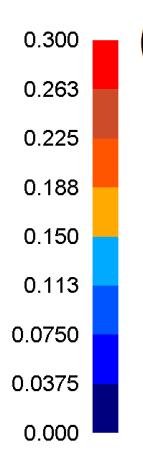

(b)

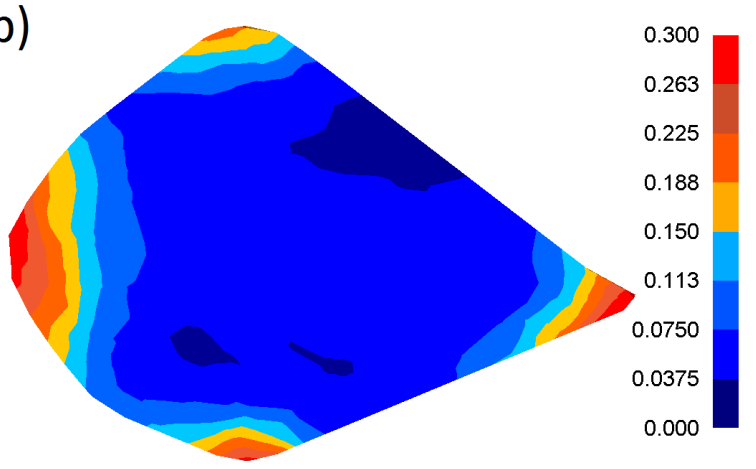

Fig. 3: Distribution of the damage factor after the cogging process): a-after the first pass $\left(\varepsilon_{h}=0.35\right) ; b$ after the second pass $\left(\varepsilon_{h}=0.70\right)$.

The twofold increase of the height reduction brought about a proportional increment in the factor $\psi_{C L}$ in the axial zone of the forging $\left(\psi_{C L}=0.05\right)$, and also an appropriate increase in the remaining strain zones (Figure $3 \mathrm{~b}$ ). The problem of the homogeneous distribution of factor $\psi_{C L}$, and also obtaining the lowest possible (permissible) values of it in the volume of the forging is a significant factor guaranteeing the maintenance of the continuity of the structure of the hard-deformable Waspaloy alloy, and the lack of damage in the course of forging. The conducted research confirmed the purposefulness of the application of asymmetrical $\mathrm{V}$-shape anvils $\left(105^{\circ} \times 135^{\circ}\right)$ for the initial cogging process of the Waspaloy alloy because the modification of the technology of plastic deformation may be conducted in the advantageous state of the three-axial compression, with simultaneous generating the low values of the factor damage 
$\psi_{C L}$. The initial structure in the cogging process ought to be completely reforged and free of damage because in the course of final die forging no elevated forging ratio are forecast. The experimental confirmation of the results of numerical research is presented in Figure 4. The strain state was determined taking advantage of the coordination grid method. The conducted comparative analysis of the effective strain with numerical calculations and obtained by means of experiments demonstrated comparatively good agreement of them.

\section{Conclusions}

The conducted assessments of the cogging process of forgings made of the Waspaloy alloy confirmed the justifiability of the application of asymmetrical V-shape anvils $\left(105^{\circ} \times 135^{\circ}\right)$. The modification of the technologies of forging may be conducted in the advantageous stress state, and it makes it possible to obtain the large values of the effective strain in the central part of the valley of strain, with simultaneous generating (in this zone) the low values of the damage factor $\psi_{C L}$, guaranteeing the cohesiveness of the plastically deformed alloy. Forecasting the billet damage in the cogging process of the Waspaloy alloy is a significant issue from the point of view of designing new technological processes.
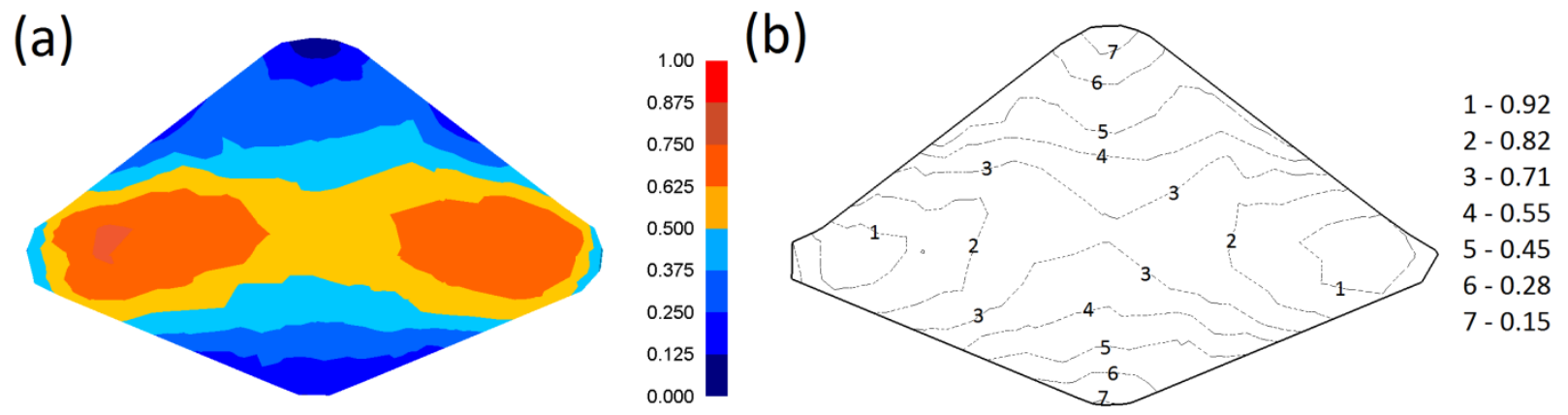

Fig. 4: Comparisons between the experimental and simulated results after the cogging process in asymmetrical $V$-shape anvils $(105 o \times 135)$ o: a- theoretical distribution of effective strain $\left(l_{w}=0.75 ; \varepsilon_{h}=0.35\right), b$ - experimental distribution of effective strain $\left(l_{w}=0.75 ; \varepsilon_{h}=0.35\right)$.

\section{References}

Kukuryk, M. (2015) Analysis of deformation and microstructural evolution in the hot forging of Ti-6Al-4V alloy. Archives of Metallurgy and Materials, 60, pp. 1639-1647.

Lin, Y.C., Chen, X.M., Wen, D.X. and Chen, M.S. (2014) A physically-based constitutive model for a typical nickel-based superalloy. Computational Materials Science, 83, pp. 282-289.

Lin, Y.C., Deng, J., Jiang, Y.Q., Wen, D.X. and Liu, G. (2014) Hot tensile deformation behaviors and fracture characteristics of a typical Ni-based superalloy. Materials and Design, 55, pp. 949-957.

Lin, Y.C., Wen, D., Deng, J., Liu, G. and Chen, J. (2014) Constitutive models for high-temperature flow behaviors of a Ni-based superalloy. Materials and Design, 59, pp. 115-123.

Swiątoniowski, A., Sińczak, J. and Łukaszek-Sołek, A. (2012) Analysis of forging process of the NiCrN superalloy for motor boat driving shaft. Archives of Metallurgy and Materials, 57, pp.719 -725.

Wang, Y., Pan, Q., Song, Y., Li, C. and Li, Z. (2013) Hot deformation and processing maps of X-750 nickel-based superalloy. Materials and Design, 51, pp. 154-160. 